\title{
Applications of Computer Aided Design to Evaluate the Zoning of Hazard Prevention in Community Neighbours
}

\author{
Kuo-Chung Wen \\ Institute of Architecture and Urban Planning, Chinese Culture University \\ Taiwan, R.O.C.
}

\section{Introduction}

The city government will provide the enough emergence routes, parks, and so on to reduce the hurtful accidents during the escape by making the urban plan. The proportions of the Zoning of Hazard prevention will be influenced by some main policy such as the develop directions, population and some effects, and sometimes get a poor proportions. So in this study we want to use some methods such as spatial and Network Analysis to set up the Zoning of Hazard prevention and estimate the safety of these area (Li, 1997).

So in this study we use Geographic Information System (GIS) to combine with the spatial information, systematize, and escape behaviour theory to simulate the escape situations. Spatial information talks about characteristic in community layout. Systematize talks about the relationship of the open space. Escape behaviour theory talks about the actions of evacuation people and simulate the escape path in the community escape path. We aimed at the community neighbours for study area. At first, we assess the escape paths and establish the relationship of the street space. Second, we set up the cell to interpret the spatial environment. Third, we suppose some types of people to simulate the escape path evacuation.

The theoretical basis of the research included Genetic Algorithms (GA). The biological evolution aroused GA, which is a kind of optimization search model within natural choice process. It operates by the way of the encoding gathered by parameter and gets rid of restrictions of seeking space analysis. For this reason, we can get the Global Optimum faster, and prevent it become the Local Optimum (Blanco, et al. 2000). Therefore, the study uses the dynamic process of the genetic calculation, and goes on the choice of the evacuation path. Receiving the batter population, we combine the function of the GIS Spatial Analysis (SA), under the disaster prevention theories, it can simulate and present a more safe model of Dynamic Path Choose Model (DPCM) that near to the behaviour of the really evacuation in mankind.

The part of DPCM could be divided into four parts. (i), is to set the population of GA operation. (ii), is to choose crossover and mutation. (iii), is to calculate the fitness function of each generation and to select the better gene arrangement. (iv), is to reproduce, after evolution, we can establish evacuation path that more reflect really human action and choice when hazard takes place. 
Finally, we compare the NA with GA calculation, and Establish real model of DPCM to choosing evacuation path. The results are three parts: 1, measure the safety of the community neighbours. 2, simulate of escape path evacuation. 3, estimate the safety area of community.

\section{Theory}

The theoretical basis of the research included GA, GIS, Network Analysis (NA) and disaster prevention theories combine with the spatial information, systematize, and escape behaviour theory to simulate the escape situations. Spatial information talks about characteristic in urban area. Systematize explain the relationship of the street networks. Escape behaviour theory talks about the actions of evacuation people and simulate the escape path in the community escape path (Breaden, 1973). The biological evolution aroused GA, which is a kind of optimization search model within natural choice processes. It operates by the way of the encoding gathered by parameter and gets rid of restrictions of seeking space analysis. For this reason, we can get the Global Optimum faster, and prevent it become the Local Optimum. Therefore, the study uses the GA and NA to goes on the choice of the dynamic flooding evacuation path. By the way, we can display the more real human behaviour and find the least cost evacuation path by the dynamic program of the data base in time. Receiving the batter population, we combine the function of the GIS Spatial Analysis, under the disaster prevention theories, it can present a more safe model that near to the behaviour of the really evacuation in mankind. The structure of combined GA with GIS is like Fig. 1.

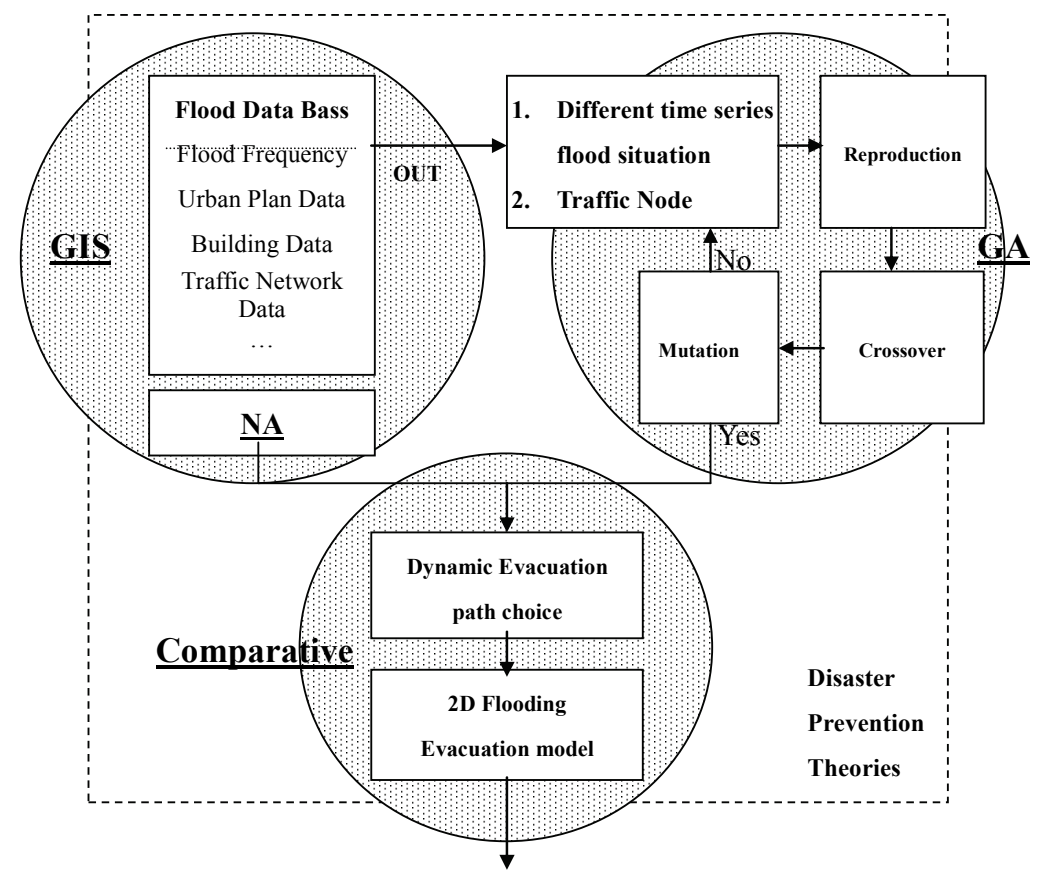

Fig. 1. The structure of combined GA with GIS 


\subsection{Disaster prevention systems}

According to the level of disaster and place, the emergence shelter should proved the functions like command post, information, disaster prevention, medical treatment, goods saving and so on. So the setting of emergence shelter should choice the local government, lodge to be the command post and the park, elementary school, community centre to be the emergence shelter.

The planning of the emergence routes are depended on the different situation. The most important function is to provide people to escape to the safety place. And according to the Taipei Disaster-Prevention Planning, The roads were classified into emergency path system, rescue transport path system, fire control path system, and assist path system (8m) (Tseng, 2000).

Zoning of hazard prevention is an independence area which is not be influence from next area and when disaster occurred the people in the area dose not escape to other ones. And the zoning area can accept enough people.

The walk speed will be closed to normal speed if there is enough space. On the contrary, if there is not enough space, walk speed will be slow down even closed to stop depending on the increasing density. Dr. Tanaboriboon and Dr. Guyano think about that walk speed and body characteristics of western is differ with oriental. At the centre street of Bangkok city in Thailand it was studied to survey location the ambulation of people (Tanaboriboon \& Guyano, 1989). They divide service level of ambulation into 6 rankings (A, B, C, D, E and F). And they convert walk speed base on the relationship of density and discharge like Table 1.

\begin{tabular}{|c|c|c|c|c|}
\hline $\begin{array}{l}\text { Services } \\
\text { level }\end{array}$ & $\begin{array}{c}\text { Density (Person / } \\
\text { Square metre) }\end{array}$ & \begin{tabular}{|c|} 
Velocity (Metre \\
/Second)
\end{tabular} & $\begin{array}{l}\text { Flow (Person / } \\
\text { Metre * Second) }\end{array}$ & Condition \\
\hline A & $<=0.42$ & $>=1.12$ & $<=0.47$ & $\begin{array}{c}\text { * Don't generate conflict each } \\
\text { other }\end{array}$ \\
\hline B & $0.43 \sim 0.63$ & $1.06 \sim 1.11$ & $0.48 \sim 0.67$ & $\begin{array}{l}\text { * The velocity and flows } \\
\text { become slightly slow }\end{array}$ \\
\hline C & $0.64 \sim 1.02$ & $1.00 \sim 1.05$ & $0.68 \sim 1.02$ & $\begin{array}{l}\text { * The pedestrian needs to } \\
\text { adjust the velocity and } \\
\text { directions }\end{array}$ \\
\hline $\mathrm{D}$ & $1.031 \sim 1.54$ & $0.88 \sim 0.99$ & $1.03 \sim 1.35$ & $\begin{array}{l}\text { * Difficult to change the } \\
\text { direction and cross }\end{array}$ \\
\hline E & $1.55 \sim 2.70$ & $0.62 \sim 0.87$ & $1.36 \sim 1.68$ & $\begin{array}{c}{ }^{*} \text { Extremely difficult to } \\
\text { change the direction and } \\
\text { cross }\end{array}$ \\
\hline $\mathrm{F}$ & $>2.71$ & $<0.61$ & $>1.69$ & $\begin{array}{c}\text { * Can't reverse direction and } \\
\text { cross }\end{array}$ \\
\hline
\end{tabular}

(Tanaboriboon \& Guyano, 1989)

Table 1. The walking services level that Tanaboriboon and Dr. Guyano established

\subsection{Dynamic programming}

We can use dynamic programming to find the suitable evacuation path. With the dynamic programming, we can establish the decide node in the time and the node of the traffic street network. And we can combine the attribute of the traffic network and some important information with GA to find the optimum Escape Path. 


\subsection{Network analyze}

Network Analyze is a way can get the optimum solution by some designate standards of the traffic network database. Networks are making up with some information which are expressing with points and lines. It is suitable to modelling roads, pipes, facilities and finds the optimum answers. Network analysis is one kind of analysis which in depended on the model of GIS system. The analysis way is to connect the spatial feature such as polygon, line and point and calculate the type and characteristic with the connecting networks (Djokie \& Maidment, 1996).

$$
\min \mathrm{z}(X)=\sum_{(i, j) \in A} \mathrm{C}_{\mathrm{ij}} X_{i j}
$$

\section{A: The set of arc in street network \\ Xij: The flow of arc $(i, j)$ \\ Cij: The cast of arc $(i, j)$}

\subsection{Genetic algorithms}

John Holland proposed genetic algorithms (GA) in 1795. This is an optimization of problem solving and technologic of machine learning. It is enlightenment from creature evolution process. The answer of every problem expresses a chromosome that present an individual creature. A group of creature were evolution by Darwin's evolutionism compete and select. The fitting creature exists that present the good solution survival the bad eliminates through competition. The new solution of new generation also to model creature propagates by survival's individual copulation and mutation (Bullock, 1995).

There are four different points between GA and traditional way of optimization and search (Woodbury 1993).

1. GA deals with whole set of solution, not only solution itself.

2. The search of GA starts from a group of population fitting well and scattering beginning, not from a point.

3. GA is objective function, not differentiation or others assist knowledge.

4. GA leads the direction of search only by hands around rule of probability.

It is a series process of self adjusts in search control of design reasoning of GA (Jo \& Gero, 1995). The combination of design reasoning rules could be a chromosome of one of evacuation path solution. Every set of chromosome is whole result of inference path generated by probability. These evolution from parents and generate next generation were selected by environment conditions. Those are constantly adjusted through heuristic rules and search strategy, stop until solution fit need. The whole process of evolution is the process of finding out answer. The final result of inference paths, evaluative rules and solution is important knowledge of evacuation path. There are three process follow:

1. Reproduction

The probability of copy from parents is derived from fitness degree of the chromosome. The common method is Roulette Wheel Selection by the percentage of its fitness degree of the chromosome over summarization of all fitness degree. That is the more high fitness degree the more opportunity to duplicate from parents.

2. Crossover

After reproduction the crossover provide for exchange chromosomes between mother generations in order to get the befitted chromosome from parents (Chan \& Tansri, 1994). 


\section{Mutation}

It may change some genes form some chromosomes to avoid lost the befit information by reproduction and crossover in the genetic process. So we can extend the searching space to escape from the local optimum to the global optimum.

\section{Modelling}

\subsection{Establish the platform}

This research carries on the construction of the development platform of the database with the geographical information system. Collect and set up relevant databases at first, then derive the model assessed in simulation and set up the data to export into interfaces. In collection of the database, will mainly collect the urban planning map and relevant attribute data, in order to build the basic geographical information system of database which constructs the calamity area, to offer basic spatial analysis and application, but the digit picture that this stage needs to finish, change of the scope of activities via presenting the time array of this area after network analysis. So must turn attribute data and spatial data into information forms of GIS, for systematic operation, it is mainly attribute data to move the urban street network, the attribute data are with the basic graph: To spread out with point, line and polygon, each of spatial data all has specific codes and corresponding attribute value, taking network layout of traffic way as an example, its attribute data include: Serial number, length, driving speed, etc. the attribute data are stored in the data form of attribute, elected fetching the data record When, figure when it is corresponding choosing. Attribute data form and basic map is construct for escape simulation of flood disaster to take special database, digital elevation model urban planning street map, floods water possibilities map, traffic network data, etc.

We use GIS to establish the system which combining the data base of the flood information. At first, we search and collect the flooding data base. And than we infer the estimating model, and set up the in put and out put of the system. About the base data, we collect the urban planning map and some correlating data to be the digital data. It can provide some applications and display the variations of the activity of the time series in the area. We divide the format into three parts, the data base are display in the shape of point, line and polygon. There are its own coding and data in each spatial object. For example, the traffic network has its own data just like coding, length, speed and so on. These data are written in the table of the data base. When you select the record, the corresponding shape will be selected. In this study, we establish these spatial data which are the topographic chart, the data of traffic network, the block of urban planning, and the flood frequency, and so on to model the evacuation path.

We study with the community neighbors. At first, we assess the Emergence route and establish the relationship of the street space. Second, we set up the cell and street networks to interpret the spatial environment. Third, we suppose some methods to simulate the Zoning of Hazard prevention evacuation and to divide the different of the Zoning of Hazard prevention (Li, 1999).

\subsection{Establish the rescue refuge rings 3.2.1 Emergence shelter}

After the basic data are collected, to city taking escape stronghold is it select to go on, as take escape to choose stronghold mainly with school, park open space mainly here of the area. 


\subsubsection{Emergence route}

Planer will take escape in the route and divide into four grades mainly while urban planning of the road value and to assess proceed of present situation, and classify the traffic network, in order to use as the follow-up network analysis.

\subsubsection{Zoning of hazard prevention}

The escape area is divide four part to mainly to set up, the major is divide into spatial geometry and network analysis two ways.

1. Spatial Geometry Analysis

With analysis and geometry of ring land that is regarded as the calculation that is rowed and had in space geometry is analyses, analysis in accordance with making and rowed and set up the space equidistantly, but several geometry analyses that separate and take escape the area with the central line in the ring land.

2. Network Analysis

Network analysis is make mathematical calculations to go on with time and distance two impedance, it is analysis to go on with unit length by each impedance value of route to hinder to resist, regard place of making it as with school export when the it can be regarded, in area can reached is it appear to go on so as to a data.

\subsection{Establish the dynamic evacuation path model}

\subsubsection{Dynamic evacuation path}

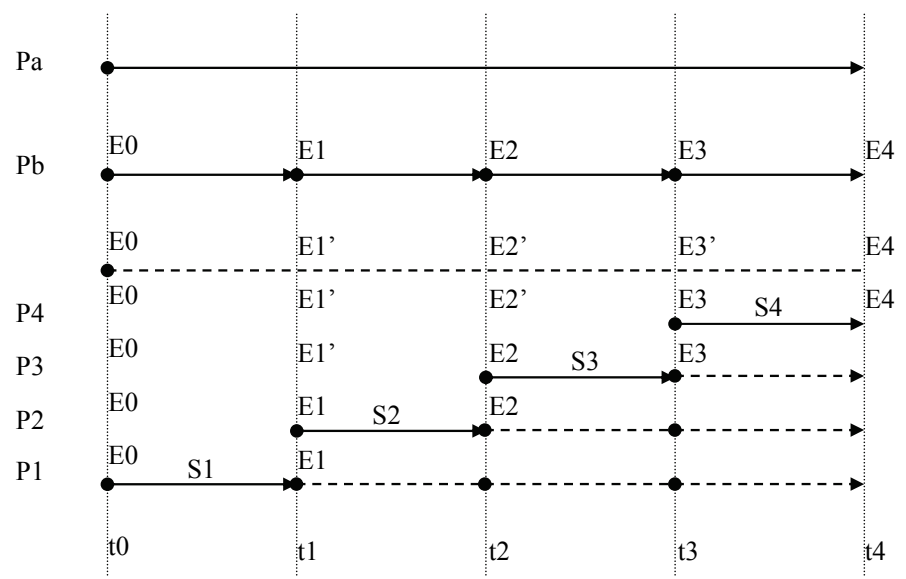

Fig. 2. The dynamic evacuation path model

We establish the evacuation path by the data of different time series. We suppose that the depth of the flood get an even rising. So we divide the time into some parts of time series. Upon the data of the time series, we can get the flood frequency in the different time series and help us to make some decision. In this study, we used different decision node in the traffic network and different time series to select the evacuation path like Fig. 2. In Fig. 2, DP is combined with S1, S2, S3 and S4, and according to the different data bases in each time series these evacuation paths. $\mathrm{E}$ is the decision nodes of path.

The dynamic evacuation path is defined by 


$$
\begin{aligned}
& D P=\left(P_{s 1 d 1}\right)_{t 1}+\left(P_{s 2 d 2}\right)_{t 2}+\ldots+\left(P_{s n d m}\right)_{t o} \\
& D P=\sum_{\substack{t=1 \\
d=1 \\
s=1}}^{n}\left(P_{s n d m}\right)_{t o}
\end{aligned}
$$

$\mathrm{d}$ : the depth of the flood ; t: the time series;

p: the moving path; s: segment of path

DP: Path Distance.

We use Best Route (BR) to calculate the optimum in this study. BR is one kind of the network analysis. It uses the minimum cumulative impedance to find the optimum with two or more traffic nodes in the traffic network. These path nodes can be sequence. And the response unite can be selected in the traffic network data items. For example, we can use the distance and time as the response unites to simulating the more real situation. So we use distance and deliver time to calculate the optimum in this study.

\subsubsection{Genetic algorithms}

The knowledge representation is the key of whole system of Evacuation Path Model (EPM). There are chromosome, environmental parameters and fitness function. These derived from path table, node table, choose table, dynamic function and GA table in GIS.

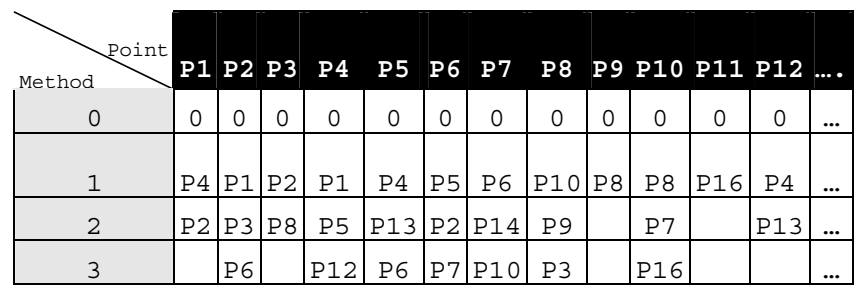

Table 2. Choose Table

\section{Code of Chromosome}

The concept is developed by initial evacuation path's idea. The result of chosen path could be transformed a serious genes to combine chromosome. Assuming one area has many nodes (for example... P1, P2, P3, ... Pn.), each node has a lot of path to be chosen. The Fig. 3 shows the node P1 has two paths can be chosen, there are two chosen method. As the same way, the P2 has three chosen method. Thus we can establish the attributes of choose table (like table 2) from node table. The table 2 presents the spatial relationship and chosen method of each node.

The dynamic function is to transform the gene code into the evacuation path (like Fig. 4). The gene code follows the id to be a chromosome in the GA. The id just the sequence number there is no any means in this table. If we decide the start node is (P1) and the end node is (P14) of evacuation path. The first id just is in the name of start node (P1), the gene code is (1). Then we can choose the next node by index the gene code from choose table. For the start node $(\mathrm{P} 1,1)$ we can index $\mathrm{P} 1$ choose the $(1)$ method to find out the P4. So the next node is $\mathrm{P} 4$, we transform the gene code from $(1,1)$ to $(\mathrm{P} 1,1)$ to $(\mathrm{P} 1, \mathrm{P} 4)$. Then repeat the steps 
above until the next node is just equal the end node. Final we can spatial join table to GIS to draw out the evacuation path (like the red line in Fig. 4).

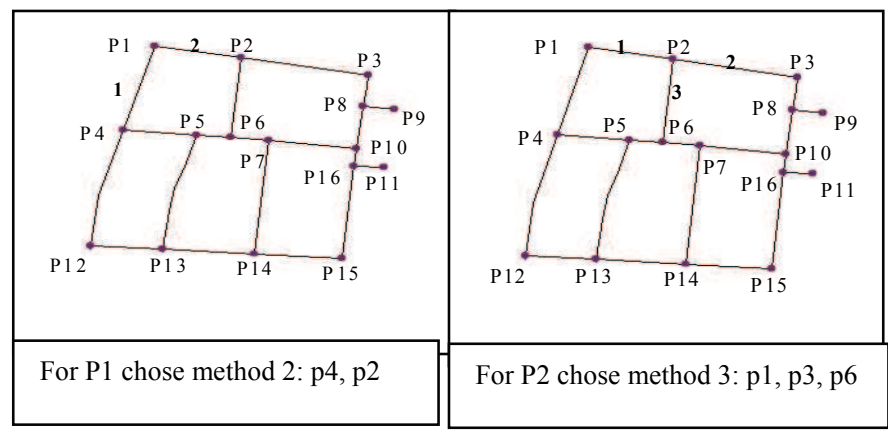

Fig. 3. The method of node choose
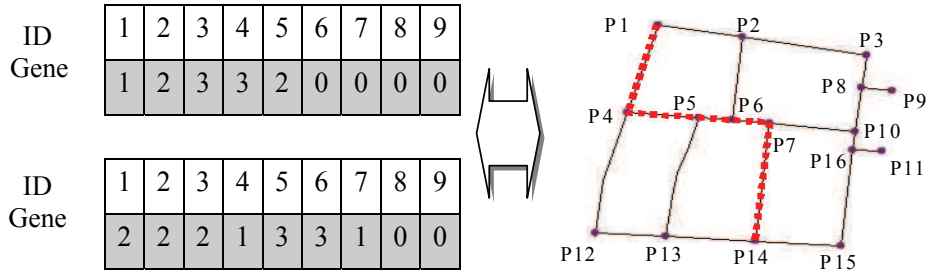

Fig. 4. The dynamic function to transform the gene code into the evacuation path

The rule of crossover between two chromosomes is before we cut any segment by random, after we crossover them.

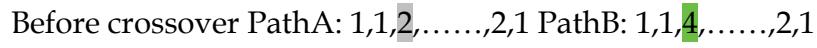

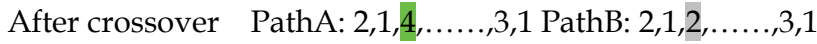

\section{Environmental Parameter}

- DF: Degree of Fitness. The value was calculated by the fitness function. Then it transfers each case's subsistence probability. The function follows:

$$
\operatorname{ALIVE}_{i}=D F_{i} / \sum_{j=1}^{n} D F_{j}
$$

DF: Degree of Fitness.

i: the i'th case

$\mathrm{j}=1$ to $n, n$ is the total cases

- PN: Population Number. The numbers of total individual, the max living numbers of controlled environment 
- $\quad$ RR: Reproduction Rate is the copy rate of mother generation. Whether the individual child will be reproduction, it depended on its subsistence probability. If the subsistence probability is higher, it will be more chance copied. It will have more opportunity to evolve.

- CR: Crossover Rate is the exchange percentage between any two chromosomes of parents.

- MR: Mutation Rate is self-change probability of any chromosome.

3. Fitness Function

The fitness function is the rules to estimate cases and give weight score. It is the tool to judge the better or worse one. It can decide to eliminate the unsuitable case. It including evaluation the rank of evacuation path, the successive nodes of evacuation path, the number of nodes, the length of evacuation path and the number of repeat path in evacuation path choose.

\section{Result}

\subsection{Computing rescue refuge rings in shiji area}

This chapter will take the Shiji City in the Keelung River Basin for case in this study. The boundary is like Fig. 5. We apply river digital topographic map, Digital Elevation Model, Traffic Network Data, Urban Planning Map, etc. According the functions required. We can analyze the demand of data, and build database.

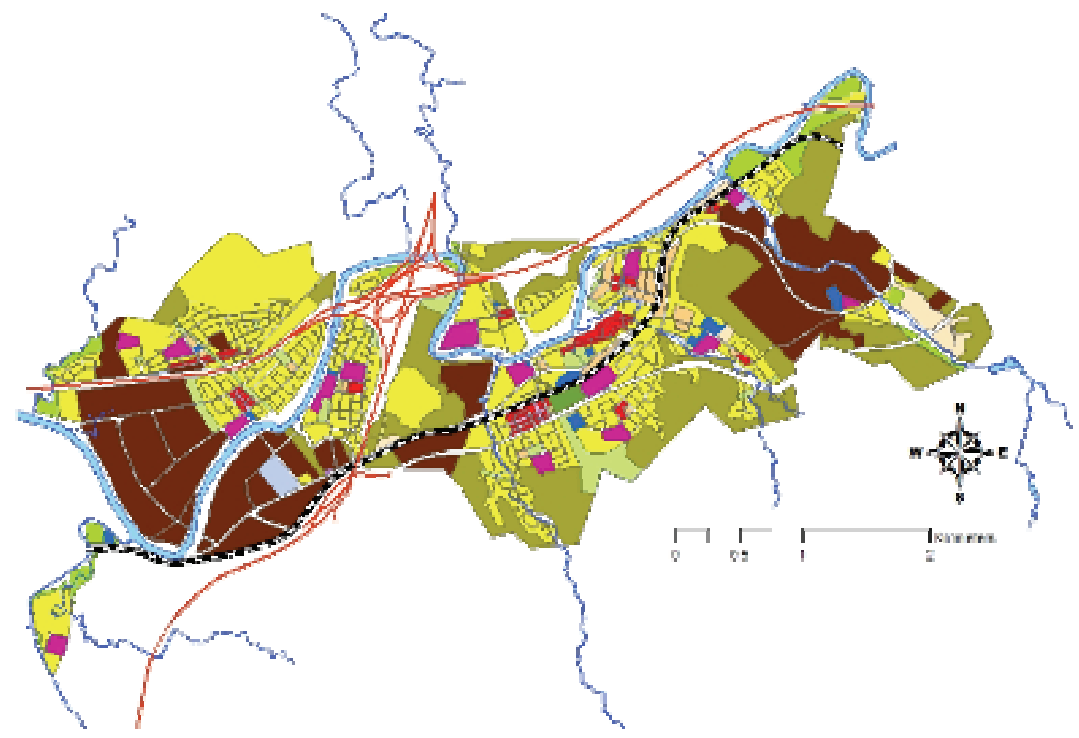

Fig. 5. the urban plan of Shiji City

\subsubsection{Emergence shelter setting}

To define the boundary of Urban Disaster Prevention \& Rescue Refuge Rings, we take the service radius $(600 \mathrm{~m})$ of high school elementary schools, and the range of refuge rings is about $300 \mathrm{~m} \sim 500 \mathrm{~m}$. The walk time of refuge rings is about $5 \sim 10$ minutes and to consider other resource of Disaster Prevention \& Rescue. The construction of the disaster prevention network model is like Fig. 6. 


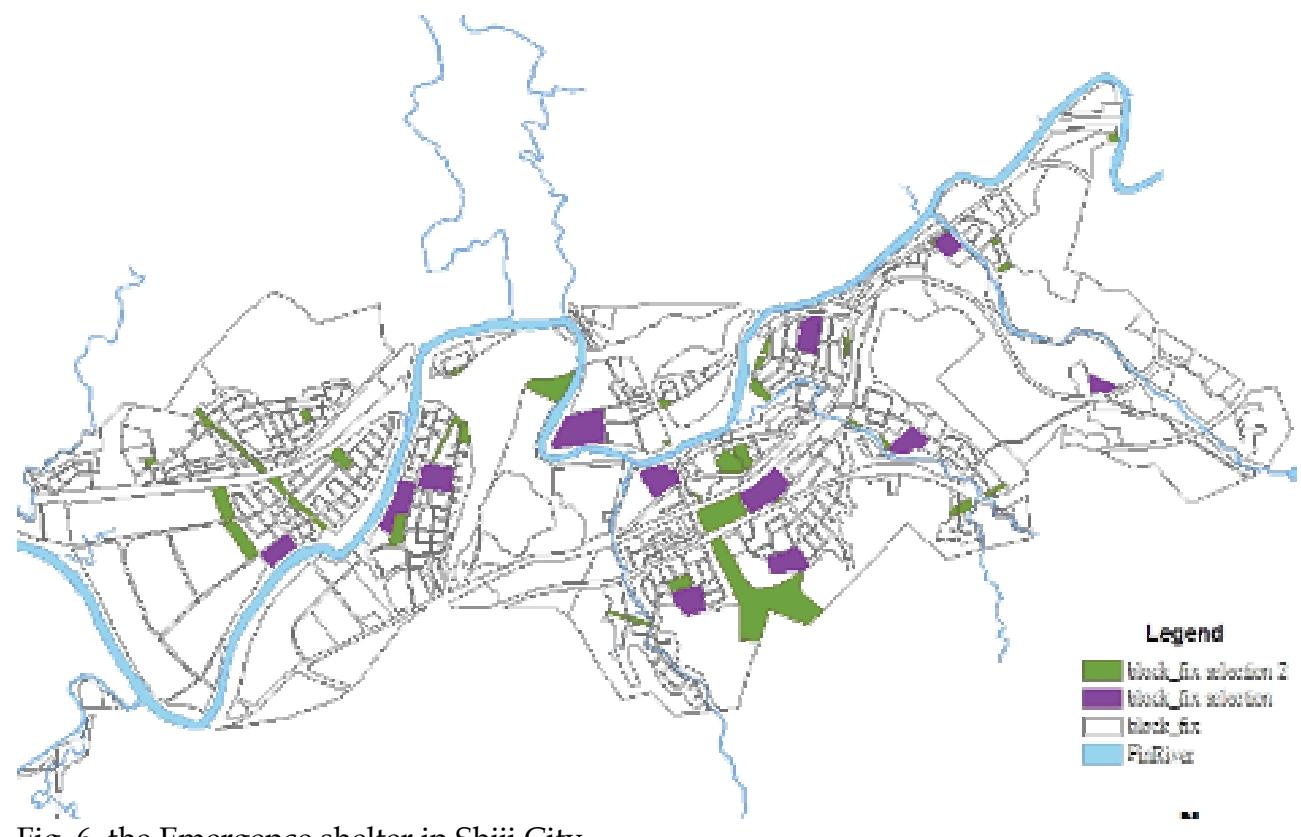

Fig. 6. the Emergence shelter in Shiji City

\subsubsection{Emergence route setting}

We adopt Taipei Disaster-Prevention Planning for the setting of road class. The roads were classified into four classes: emergency path system $(20 \mathrm{~m})$ rescue transport path system $(15 \mathrm{~m})$ fire control path system $(8 \mathrm{~m})$ and assist path system $(8 \mathrm{~m})$, like Fig. 7.

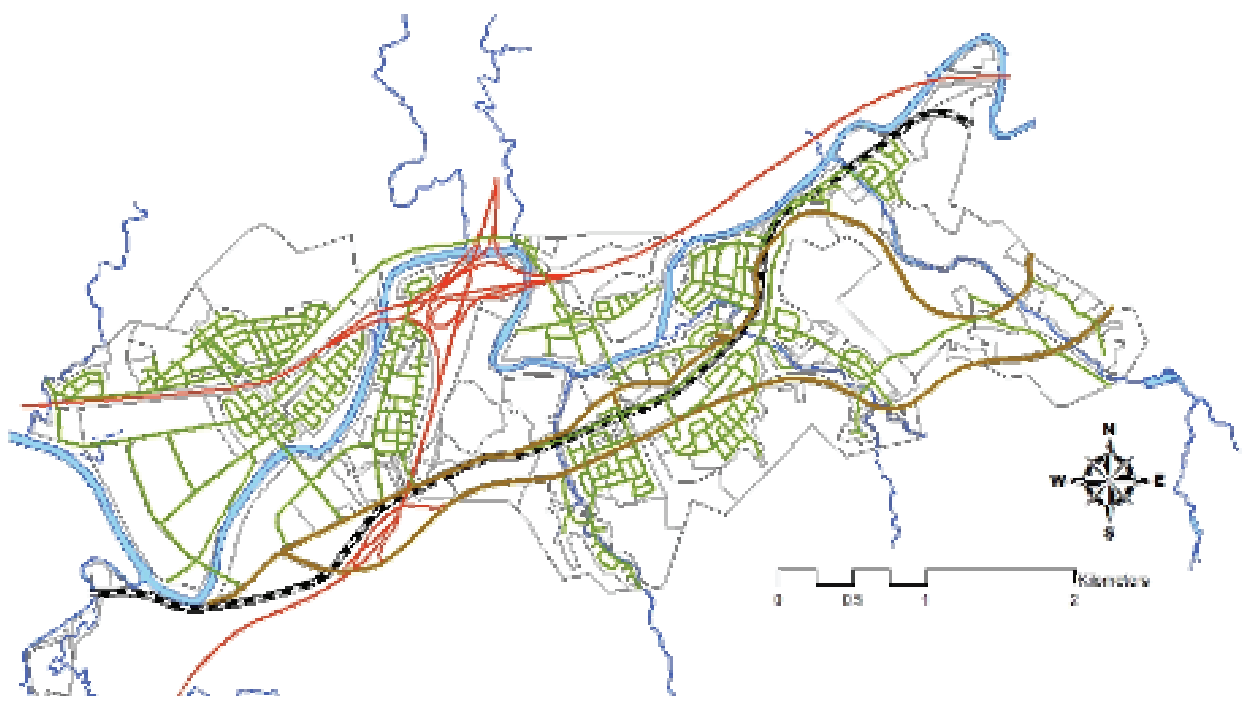

Fig. 7. the Emergence route in Shiji City 


\subsubsection{Zoning of hazard prevention setting}

The zoning of hazard prevention are calculate by spatial and network analysis. We use schools to be the Emergence shelter and the emergence routes to calculate the area of network.

1. Spatial Geometry Analysis

We use the center of schools to be the point and calculate the perpendicular bisector in the area you can use the shortest distance to the Emergence shelter. Like Fig. 8.

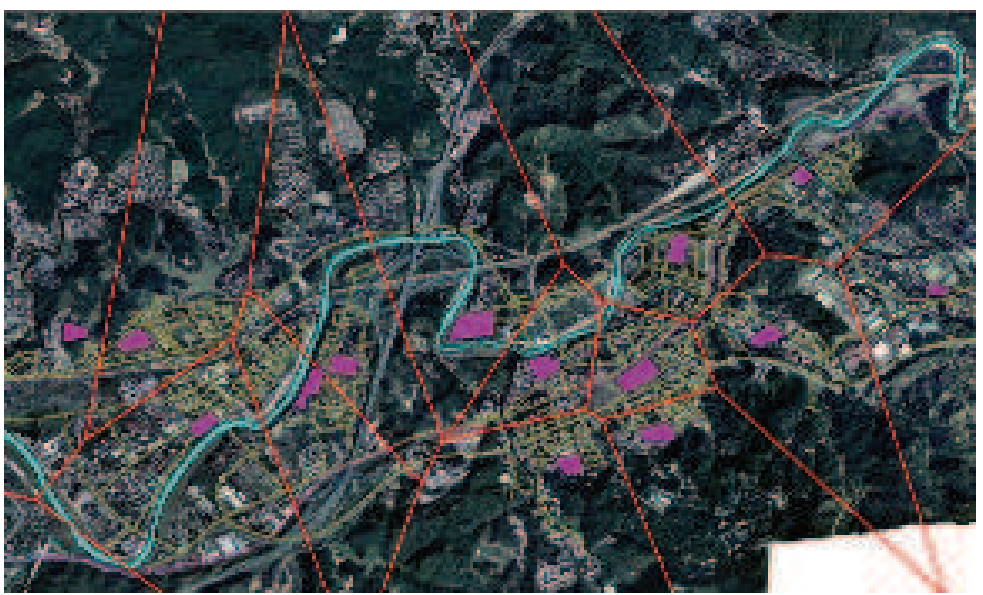

Fig. 8. Calculate by Spatial Geometry Analysis

We also use buffer to calculate the same distance area to be the refuge rings. In Fig. 9, we use the distance of $500 \mathrm{~m}$ to display the area of near ones. Some area cover the same place and some place are not covered.

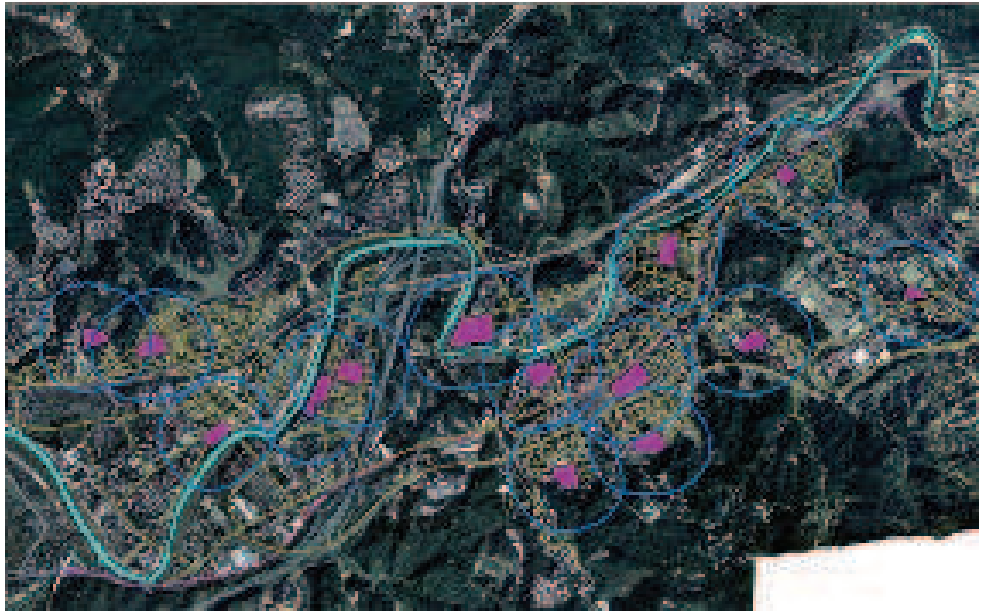

Fig. 9. Calculate by buffer analysis

2. Network Analysis

In this study, we use distance and deliver time to be the cast of the weighting. By distance we calculate the network with 500m, like Fig. 10. 


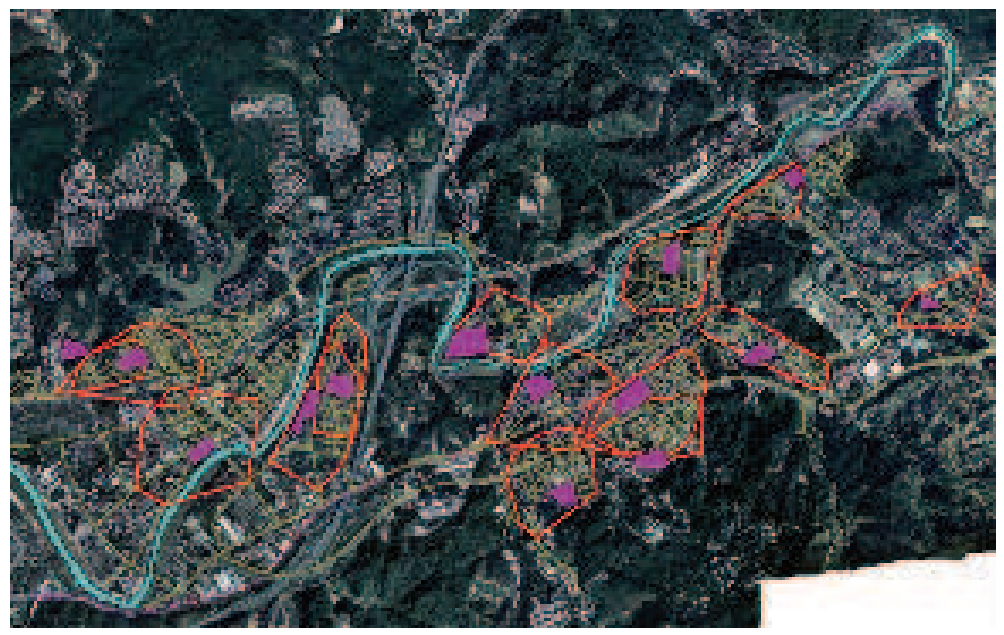

Fig. 10. Calculate by network Analysis (distance)

About the deliver time, we use 10 minutes to display the service area, like Fig. 11. some area have different level emergence routes, so in this service area the distance of road will be change by difference level routes.

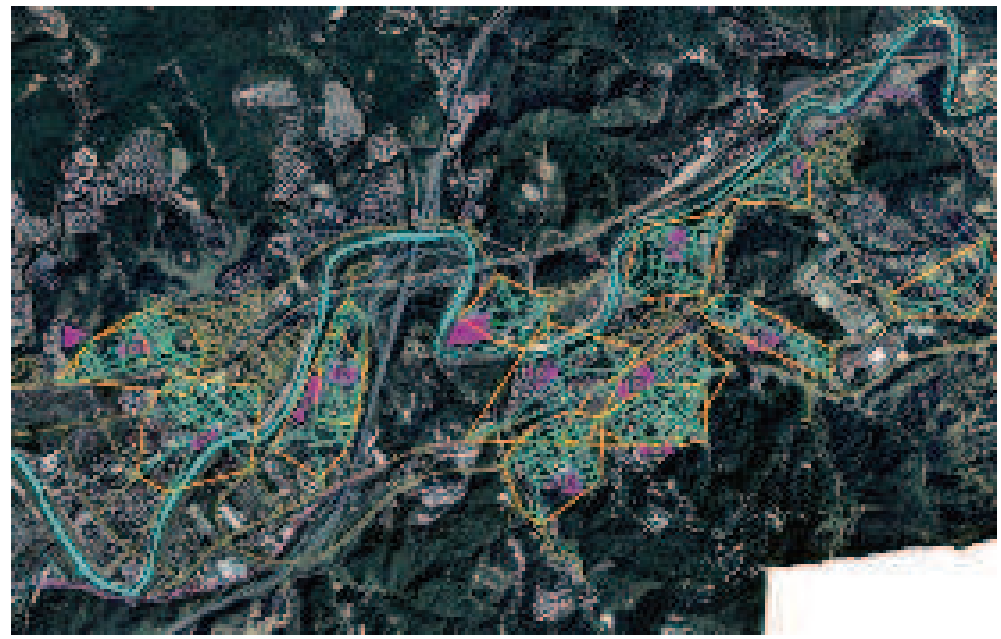

Fig. 11. Calculate by network Analysis (deliver time)

3. Zoning of Hazard Prevention

When look into the large scale, we can find the refuge rings with different shapes. In Fig. 1215, we can find the relationship between the Emergence shelter and Zoning of Hazard prevention. 


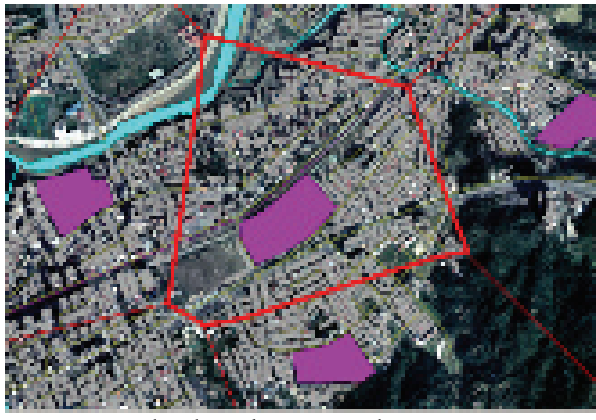

Fig. 12. Calculate by spatial geom.etory analysis

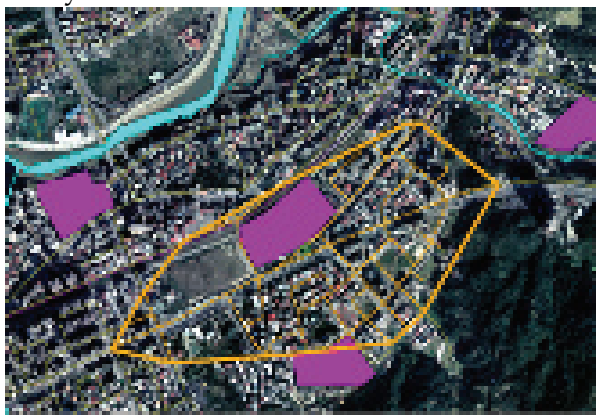

Fig. 14. Calculate by network analysis (10min)

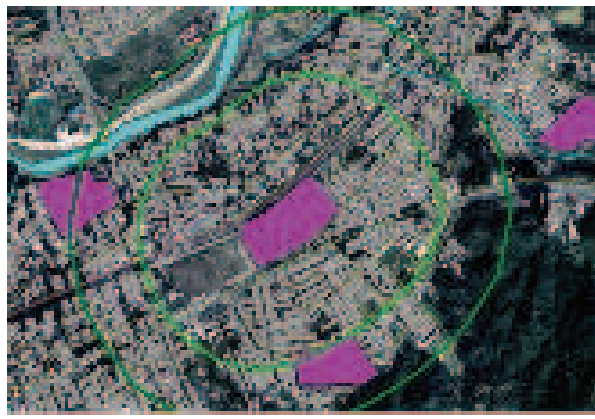

Fig. 13. Calculate by buffer analysis (300, $500 \mathrm{~m})$

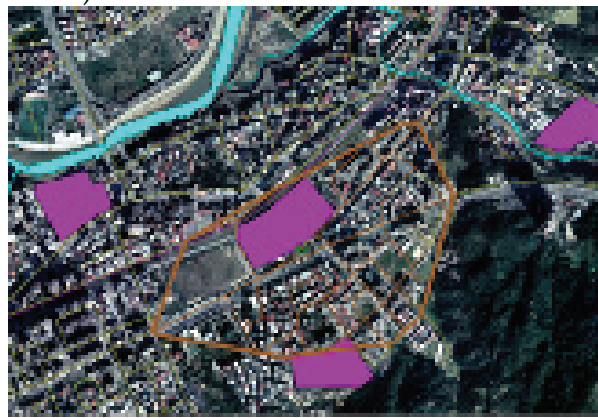

Fig. 15. Calculate by network analysis (500m)

In Fig. 16. we can compare with this area of Zoning of Hazard prevention, we can find the different area and facility.

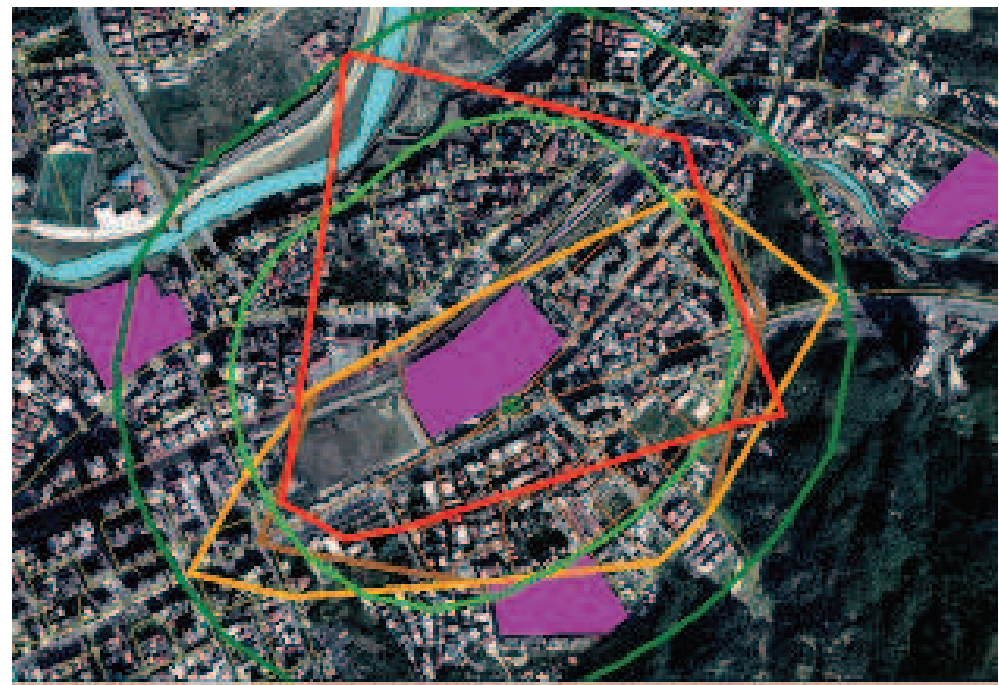

Fig. 16. Compare the plan of Zoning of Hazard prevention 
With the data of geometry and facility, we can compare the value of plan property like table 3.

\begin{tabular}{|c|c|c|c|c|c|}
\hline Type & AREA & Perimeter & Road & Building & Zoning \\
\hline Geometry & 496759 & 2835 & 7811.9 & 141089 & 576189 \\
\hline Buffer-300 & 556097 & 2681 & 8370.1 & 176605 & 730407 \\
\hline NA-D500 & 455940 & 2828 & 9086.2 & 135375 & 604954 \\
\hline NA-T10 & 379754 & 2467 & 8234.9 & 119762 & 531208 \\
\hline
\end{tabular}

Table 3. the data of spatial information

We can use the data to calculate the efficiency of the plans, in table 4, we use some formula to estimate the emergence system. We use the building coverage ratio and zoning area to calculate the service efficiency. By using the floor space index floor area ratio and Emergence shelter area to presume the population. The road and area and rate can talk about the efficiency and the area type also can be assessed to the potency.

\begin{tabular}{|c|c|c|c|c|}
\hline TYPA & $\mathrm{P}$ P/A & R/A & $\mathrm{B} / \mathrm{A}$ & $\mathrm{Z} / \mathrm{A}$ \\
\hline geometry & 16.17 & 0.0157 & 0.28 & 1.15 \\
\hline Buffer-300 & 12.92 & 0.0150 & 0.31 & 1.31 \\
\hline Buffer-600 & 12.78 & 0.0123 & 0.24 & 1.15 \\
\hline NA-D500 & 17.54 & 0.0199 & 0.29 & 1.32 \\
\hline NA-T10 & 16.02 & 0.0216 & 0.31 & 1.39 \\
\hline
\end{tabular}

Table 4. the estimate of emergence system

We establish the master place to calculate the variation of the Emergence shelter like Fig. 17-20.

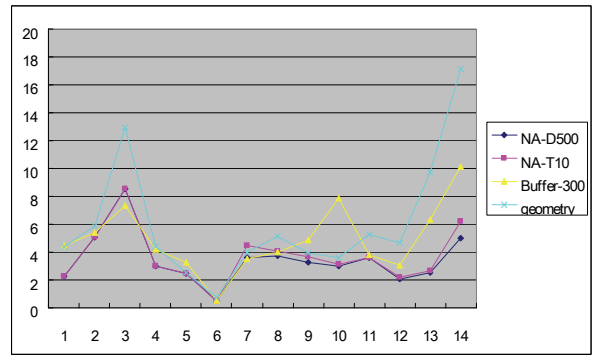

Fig. 17. the variation of plan efficiency

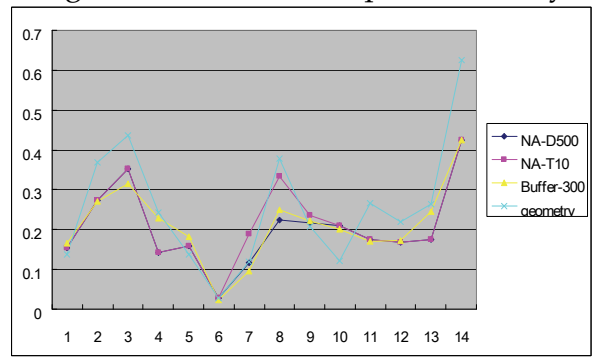

Fig. 19. the variation of acceptability

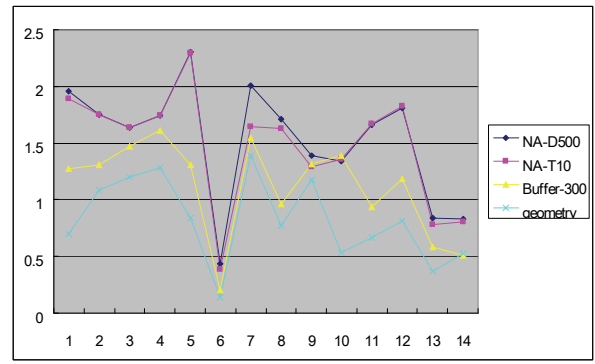

Fig. 18. the variation of population

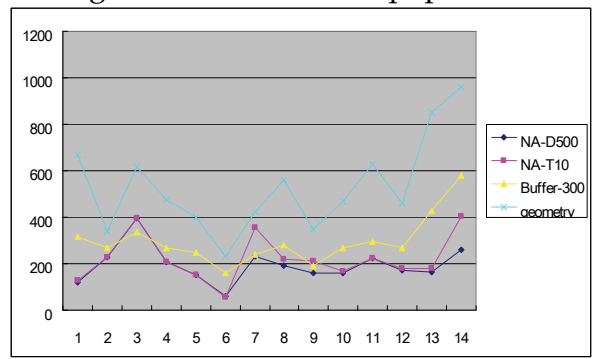

Fig. 20. the variation of spatial service 


\subsection{Computing evacuation path in shiji area}

This chapter will take the Shiji City in the Keelung River Basin for case in this study. The boundary is like Fig. 21. We apply river digital topographic map, Digital Elevation Model, Traffic Network Data, Urban Planning Map, etc. According the functions required. We can analyze the demand of data, and build database.

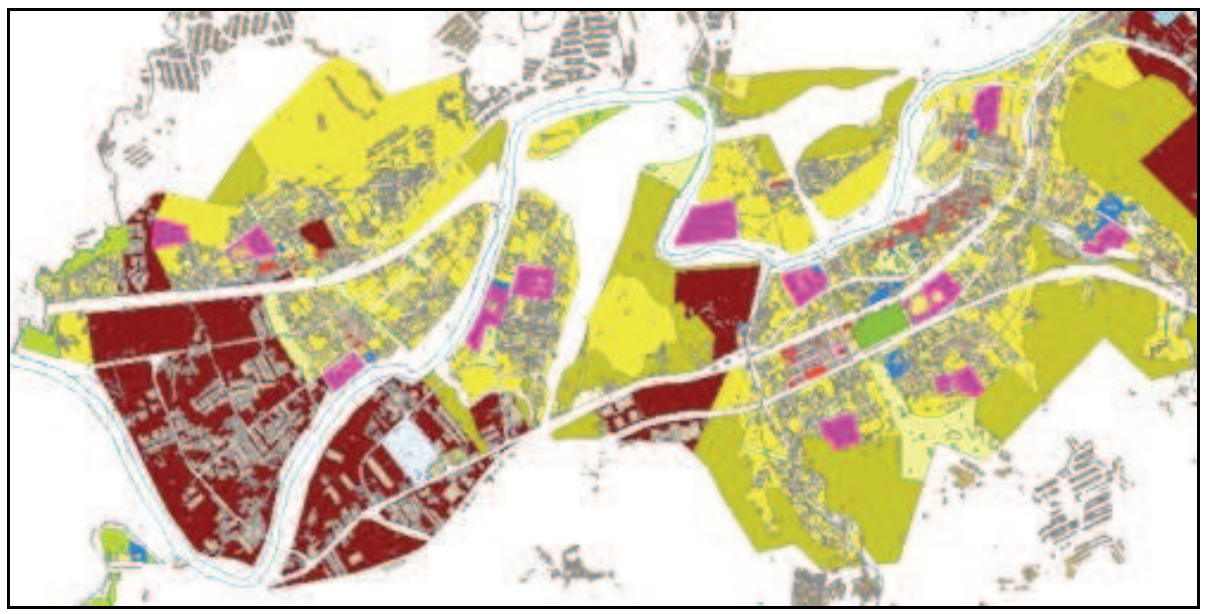

Fig. 21. The Region of Shiji

\subsubsection{Establish the traffic street network}

We adopt Taipei Disaster-Prevention Planning for the setting of road class. The roads were classified into four classes: emergency path system $(20 \mathrm{~m})$ rescue transport path system $(15 \mathrm{~m})$ fire control path system $(8 \mathrm{~m})$ and assist path system $(8 \mathrm{~m})$. To define the boundary of Urban Disaster Prevention \& Rescue Refuge Rings, we take the service radius $(600 \mathrm{~m})$ of high school elementary schools, and the range of refuge rings is about $300 \mathrm{~m} \sim 500 \mathrm{~m}$. The walk time of refuge rings is about 5 10 minutes and to consider other resource of Disaster Prevention \& Rescue. The construction of the disaster prevention network model is like Fig. 22.

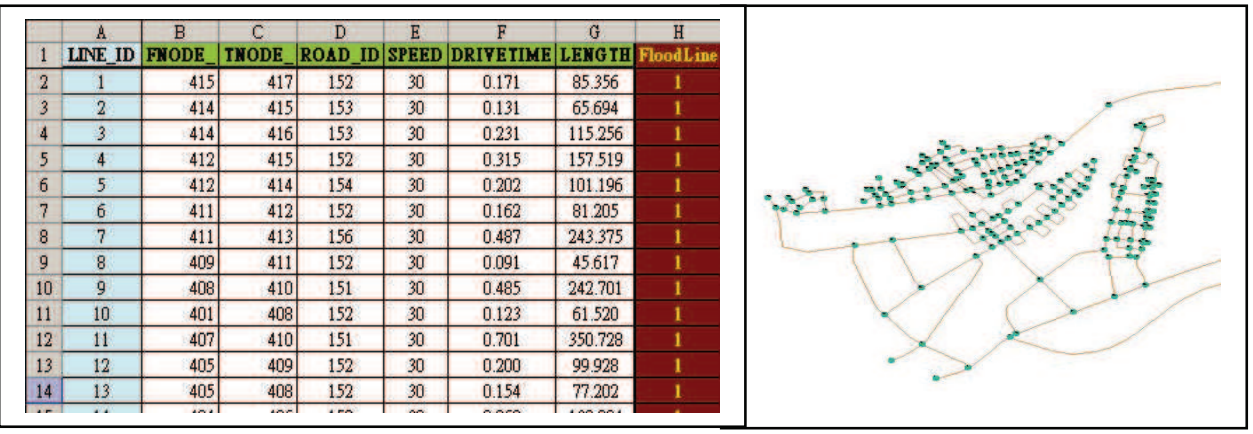

Fig. 22. Disaster prevention network data establishment 


\subsubsection{Network analysis of the evacuation path}

This part we use Best Route to calculate the optimum. We use distance and deliver time to search for the least accumulative cost like Fig. 23 and Fig. 24. In Fig. 23, Best Route calculates the least accumulative cost by the distance. But in Fig. 24 is depends on deliver time. There are some different evacuation paths in the tow figure. The reason of the different is the class of the path. The high level paths get the short deliver time, but these cost more distance. So we get the different optimum with Best Route.

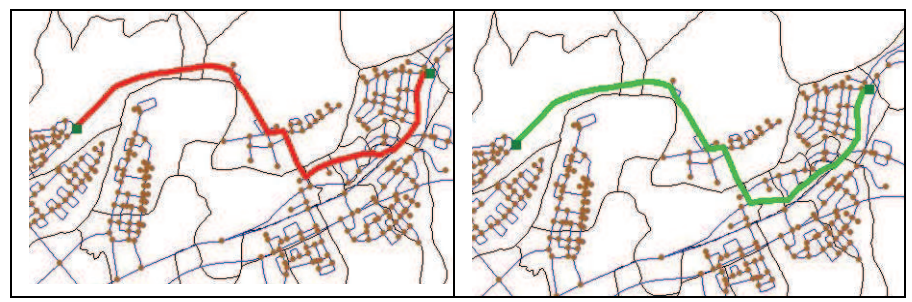

Fig. 23. \& Fig. 24. Network Analysis of the Evacuation Path

\subsubsection{Working data and parameter setting}

Before process the GA calculation, we must to precede the pattern of Gene Coding. Let the variables indicate the suitable sequence in the computer operating. And we decoding it and return the result (like Fig. 25).

Final we set the parameter like Initial population, crossover rate and mutation rate. After we coding the refuge node, we can create initial population and choose the start node. This study on GA's parameter set up 1500 initial populations, and it has $0.5 \%$ crossover rate and $0.1 \%$ mutation rate.

\begin{tabular}{|c|c|c|c|c|c|c|c|c|c|c|c|}
\hline & A & B & C & D & E & F & G & $\mathrm{H}$ & I & $\mathrm{J}$ & $\mathrm{K}$ \\
\hline 1 & Node ID & PathNum & TMODE1 & TMODE2 & TMODE 3 & TMODE4 & Flood Sode & LINE IDI & LINE ID2 & LINE ID3 & LINE ID4 \\
\hline 2 & 1 & 1 & 2 & & & & 1 & 584 & 0 & 0 & 0 \\
\hline 3 & 2 & 3 & 1 & 10 & 11 & & 1 & 584 & 583 & 582 & 0 \\
\hline 4 & 3 & 1 & 6 & & & & 1 & 581 & 0 & 0 & 0 \\
\hline 5 & 4 & 1 & 10 & & & & 1 & 580 & 0 & 0 & 0 \\
\hline 6 & 5 & 1 & 6 & & & & 1 & 579 & 0 & 0 & 0 \\
\hline 7 & 6 & 3 & 3 & 5 & 8 & & 1 & 581 & 579 & 578 & 0 \\
\hline 8 & 7 & 1 & 8 & & & & 1 & 576 & 0 & 0 & 0 \\
\hline 9 & 8 & 3 & 6 & 7 & 9 & & 1 & 578 & 576 & 574 & 0 \\
\hline 10 & 9 & 3 & 8 & 12 & 12 & & 1 & 574 & 573 & 575 & 0 \\
\hline 11 & 10 & 4 & 55 & 2 & 4 & 19 & 1 & 571 & 583 & 580 & 572 \\
\hline 12 & 11 & 3 & 13 & 36 & 2 & & 1 & 570 & 577 & 582 & 0 \\
\hline 13 & 12 & 3 & 9 & 9 & 15 & & 1 & 573 & 575 & 569 & 0 \\
\hline 14 & 13 & 4 & 125 & 21 & 31 & 11 & 1 & 407 & 567 & 568 & 570 \\
\hline 15 & 14 & 1 & 15 & & & & 1 & 566 & 0 & 0 & 0 \\
\hline 16 & 15 & 3 & 12 & 14 & 17 & & 1 & 569 & 566 & 565 & 0 \\
\hline 17 & 16 & 1 & 22 & & & & 1 & 564 & 0 & 0 & 0 \\
\hline 18 & 17 & 3 & 18 & 15 & 20 & & 1 & 562 & 565 & 563 & 0 \\
\hline 19 & 18 & 1 & 17 & & & & 1 & 562 & 0 & 0 & 0 \\
\hline 20 & 19 & 3 & 25 & 10 & 70 & & 1 & 560 & 572 & 561 & 0 \\
\hline 21 & 20 & 3 & 24 & 17 & 22 & & 1 & 558 & 563 & 559 & 0 \\
\hline
\end{tabular}

Fig. 25. The refuge node coding

To search evacuation path, we use GA technique to get an answer belong to the problem form of the limited type model. The region of answer could be very small. The result could be segment to several areas. It would have low rate to get optimization answer with this model, and the rate of best answer also obvious level down. Generally speak the best answer often appearance on cape area that on the boundary region of the feasible solution. If we only adopt the information of the feasible solution, it would increase search time and difficulty. 
Gen (1997) use GA to solve the limited type of problem model, it will often appear the result that not falls into feasible solution region. Gen solve these problems by four kinds of strategy, we use two kinds of methods in the following (Gen, M. and Miller, 1997).

1. Reject Strategy

Once the answer of GA output in not feasible solution region, we throw down that chromosome right away. Make sure the chromosome that making duplicate always in the feasible solution region.

2. Penalty Strategy

At original target function, increase a penalty item. The penalties items will check by the level of individual act against restrict. The degree of act against is more. The penalty function is bigger. Whereas is smaller. These study give different degrees of penalty function with have inundation or not. So we can make the limit question into in limit.

\subsubsection{Operation interface and process}

On the process of searching the best evacuation path, we adopt two different methods to find the solution. First, it is on the condition of evacuation path continuous each other and processes the optimization of path. Second, it is on the unlimited condition, so all influential factor proceed in different indicators weights. The first method has better searching speed, the second method has longer time to calculate, but it is flexible. In this study, we take the first method to simulating. The operation interface is like Fig. 26. The Population Results and Progress Graph like Fig. 27.

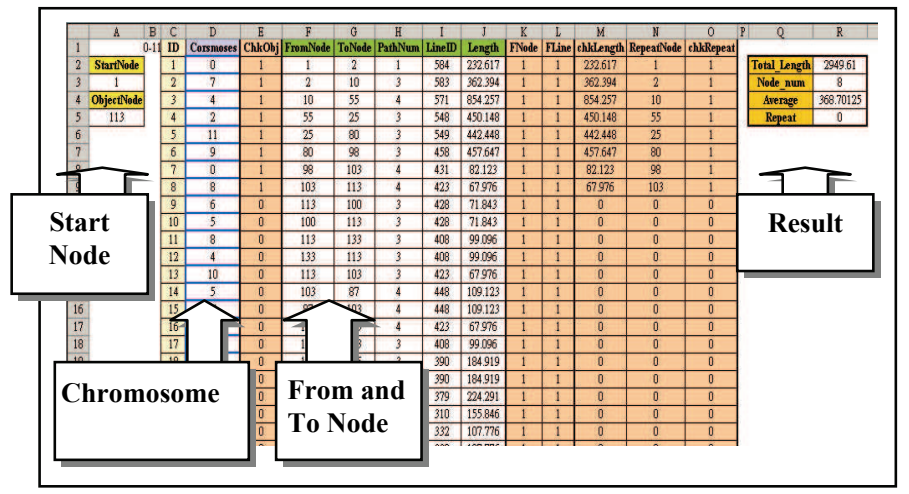

Fig. 26. Operation interface
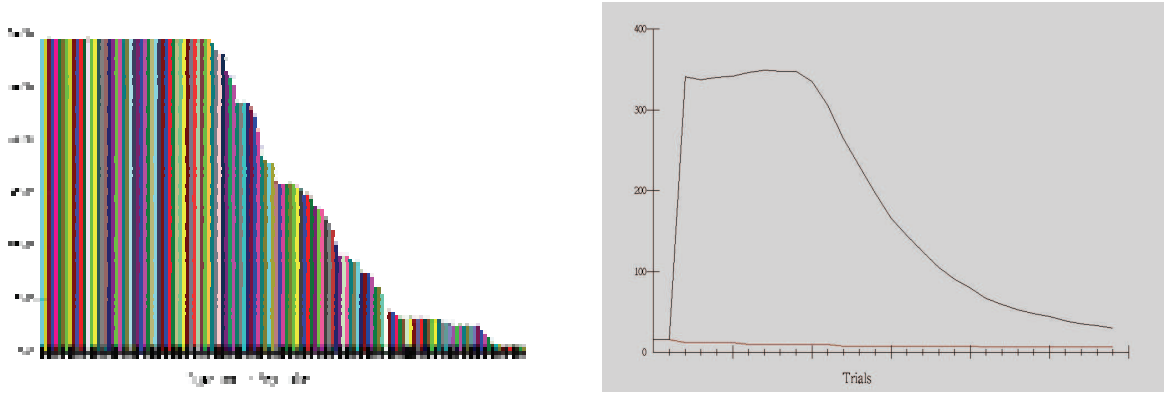

Fig. 27. Population Results and Progress Graph 


\subsubsection{The Simulation of the dynamic evacuation path by GA}

We calculate the different evacuation path with the data base in the first and sixteen time series by GA. According to the depth of the flood frequency of the time series, GA search for the optimum are distinct like Fig. 28 and Fig. 29. In the first time series GA get the smooth evacuation path. In the Fig. 28 GA calculate the evacuation path with the first time series data, and some data base of the traffic network are unhindered. But in the sixteen time series the data of traffic network get more resistance. So the optimums of evacuation path get a more distance like Fig. 29.

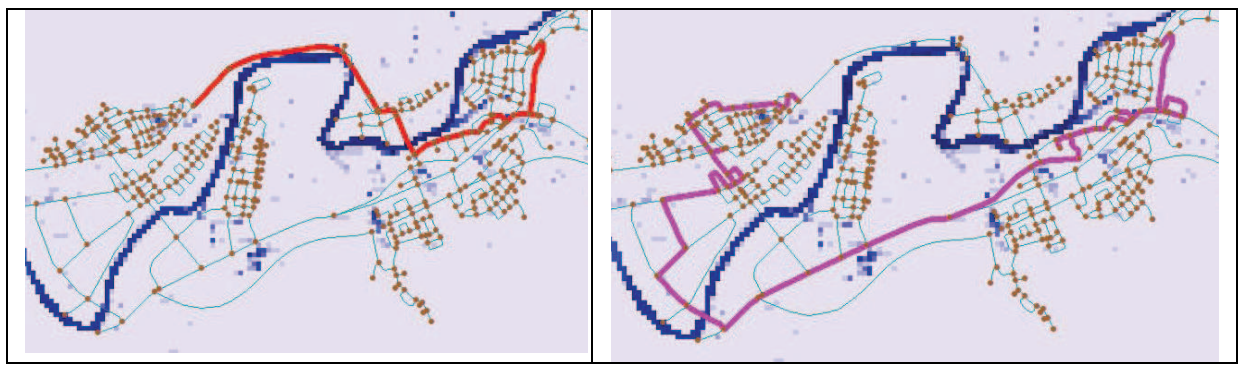

Fig. 28 \& Fig. 29. Population Results and Progress Graph

We use the dynamic program to calculate the sequence evacuation paths in different time series. If we set up the more decision nodes, we will get the more real Dynamic Evacuation Path. With the different data base of time series, we divided the time series into three parts. At first, we set up the same destination. We use the data base of the first hour. And it gets the first part of evacuation path like Fig. 30. Second, we try to set up the traffic node to be the first decision node in the first part of evacuation path. Third, we use the fifth hour data to be the second time series. And calculates the evacuation path from the first decision node and get the second part of evacuation path. Forth like Fig. 31, we set up the second decision node from the second part of evacuation path, and use the data base of ninth hour to be the third time series. We use GA to calculate the evacuation path from the second decision node and get the second part of evacuation path like Fig. 32. Finally, we combined with the three parts of evacuation path to be the Devacuation path like Fig. 33.

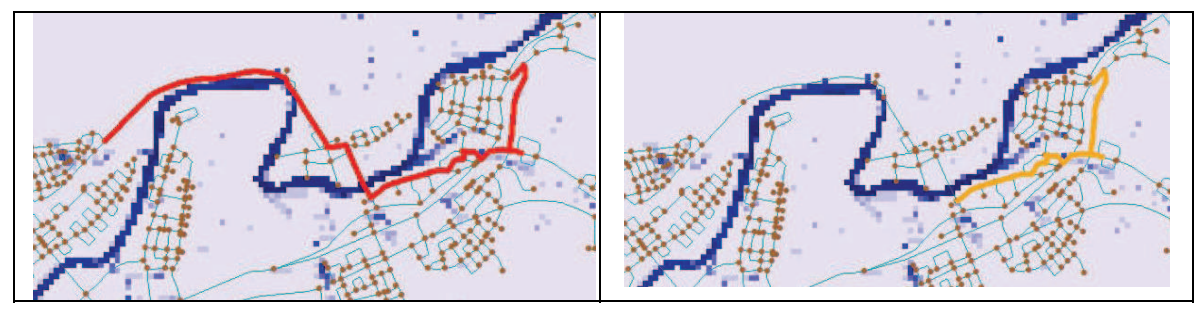

Fig. 30 \& Fig. 31.The evacuation path of the First Time Series and the Second Time Series

\subsubsection{Comparative the evacuation path of NA and GA}

In this study we get the different evacuation path by using the NA and GA calculations. The evacuation path of the NA is depending with the least accumulative cost by deliver time. So the simulation of evacuation path choices the fast moving path which is not depends on the least distance. The evacuation path of NA is green color in the Fig. 34. 


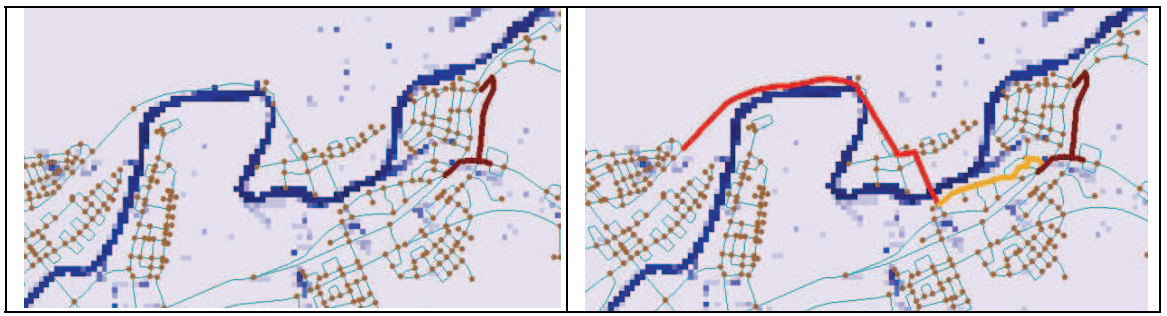

Fig. 32 \& Fig. 33 .The evacuation path of the Third Time Series and the dynamic evacuation path of GA

The GA searches the optimum by coding, the weight of the data base of the traffic network and penalty function. So the simulation of the GA's evacuation path in some path avoids the depth of flood. The evacuation paths of GA are brown, yellow and red color in the Fig. 34 .

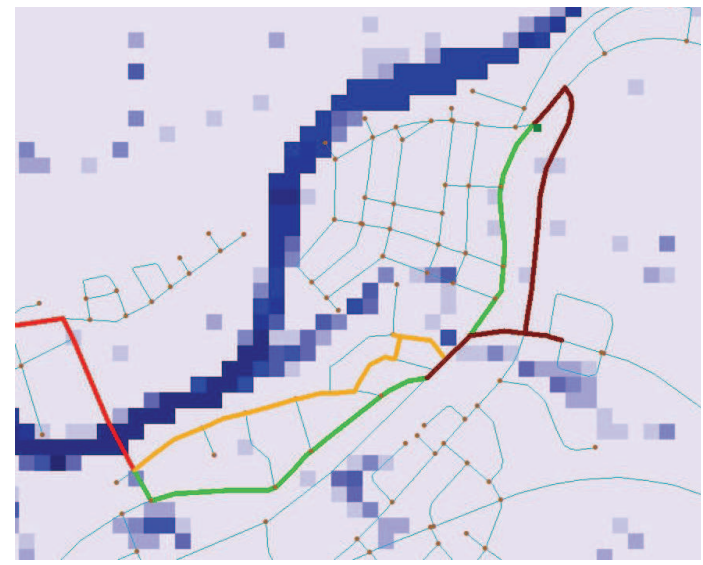

Fig. 34. The Comparative the evacuation path of GA and NA

\section{Conclusion}

In this study, we use the spatial information, systematize, and escape behaviour theory to establish the zoning of Hazard prevention. And compare the spatial information and some data of facility. By using this number we can understand the plan of the place. We just treat the shape of the zoning Hazard prevention, some area should regulate in some spatial objects to conform the more real situation. Also, we establish disaster databases to proceed with case study and bring up the preliminary analysis result, Combining GA and GIS to deal with the dynamic time space data, we point on the different selections of the path with the GA and NA, and the simulation can offer the better hermeneutic capability to process dynamic flooding evacuation path modal. We constructing the database of dynamic time and spatial and the pattern of analyzing evacuation path, and to propose the method of combination further, and analyze the process of the combination of spatial and time information. Using dynamic program to simulate the evacuation path by calculating with the different time series with these decision nodes which are in the traffic network can 
provide the more real situation. NA can set up more suitable data base which are according to the flood data to simulate the more real situation with the time series. With the suitable data NA search the optimum with the least accumulative cost will more flexible. GA searches the optimum by chromosome operation. The different methods of coding and penalty function may make up the different optimums. So taking a look at the methods is important operation to search the optimum.

\section{References}

Blanco, A.; Delgado, M. \& Pegalajar, M. C., (2000). A Genetic Algorithm to Obtain the Optimal Recurrent Neural Network, International Journal of Approximate Reasoning, pp.67-83.

Breaden, J. P. (1973). The Generation of Flood Damage Time Sequences, University of Kentucky Water Resources Institute Paper, NO.32.

Bullock, G. N. (1995). Developments in the use of the genetic algorithm in engineering design, Design Studies, 16: 507-524.

Chan, K. C. \& Tansri, H. (1994). A Study of Genetic Crossover Operations on the Facilities Layout Problem, Computers Ind. Engr. 1994, 26(3): 537-550.

Djokie, D. \& Maidment, D. R. (1996). Application of GIS Network Rountines for Water Flow and Transport, Journal of Water Resources Planning and Management, ASCE, 119(2): 229-241.

Gen, M. \& Miller, L. (1997). Foundation of Genetic Algorithms, Genetic Algorithms \& Engineering Design, pp.1-41.

Jo, J. H. \& Gero, J. S. (1995). A Genetic Search Approach to Space Layout Planning, in Architectural Science Review, 1995, Vol.38, pp.37-46.

Li, W. (1997). The layout of Taipei City Planning Disaster Prevention System, R.O.C. city planning academic association.

Li, W. (1999). Study on the functions of urban disaster-prevention of physical-environment in a city though comparing with the urban disaster prevention system (II), Architecture \& Building Research Institute Ministry of interior, Research Project report, Taipei.

Tanaboriboon, Y. \& Guyano, J. (1989). Level of Services Standards for Pedestrian Facilities in Bangkok: A Case Study, ITE Journal, pp. 39-41.

Tseng, M. \& Chen, S. (2000). A study on the evaluation methods of the emergency routes in the urban area (II), Architecture \& Building Research Institute Ministry of interior, Research Project report, Taipei.

Woodbury, R. F. (1993). A Genetic Approach to Creative Design, in Modeling Creativity and Knowledge-Based Creative Design, edits Gero, J. S. and Maher, M. L., pp.211-232. 


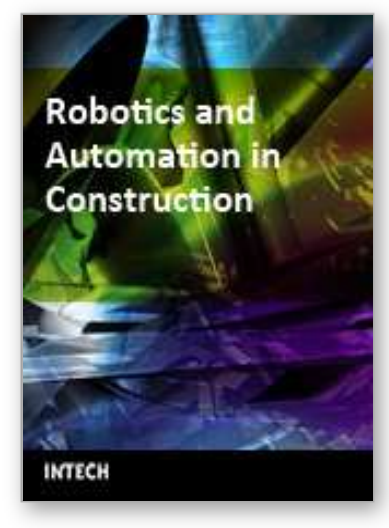

\author{
Robotics and Automation in Construction \\ Edited by Carlos Balaguer and Mohamed Abderrahim
}

ISBN 978-953-7619-13-8

Hard cover, 404 pages

Publisher InTech

Published online 01, October, 2008

Published in print edition October, 2008

This book addresses several issues related to the introduction of automaton and robotics in the construction industry in a collection of 23 chapters. The chapters are grouped in 3 main sections according to the theme or the type of technology they treat. Section I is dedicated to describe and analyse the main research challenges of Robotics and Automation in Construction (RAC). The second section consists of 12 chapters and is dedicated to the technologies and new developments employed to automate processes in the construction industry. Among these we have examples of ICT technologies used for purposes such as construction visualisation systems, added value management systems, construction materials and elements tracking using multiple IDs devices. This section also deals with Sensorial Systems and software used in the construction to improve the performances of machines such as cranes, and in improving Human-Machine Interfaces (MMI). Authors adopted Mixed and Augmented Reality in the MMI to ease the construction operations. Section III is dedicated to describe case studies of RAC and comprises 8 chapters. Among the eight chapters the section presents a robotic excavator and a semi-automated façade cleaning system. The section also presents work dedicated to enhancing the force of the workers in construction through the use of Robotic-powered exoskeletons and body joint-adapted assistive units, which allow the handling of greater loads.

\title{
How to reference
}

In order to correctly reference this scholarly work, feel free to copy and paste the following:

Kuo-Chung Wen (2008). Applications of Computer Aided Design to Evaluate the Zoning of Hazard Prevention in Community Neighbours, Robotics and Automation in Construction, Carlos Balaguer and Mohamed Abderrahim (Ed.), ISBN: 978-953-7619-13-8, InTech, Available from:

http://www.intechopen.com/books/robotics_and_automation_in_construction/applications_of_computer_aided_ design_to_evaluate_the_zoning_of_hazard_prevention_in_community_neigh

\section{INTECH}

open science | open minds

\section{InTech Europe}

University Campus STeP Ri

Slavka Krautzeka 83/A

51000 Rijeka, Croatia

Phone: +385 (51) 770447

Fax: +385 (51) 686166

\section{InTech China}

Unit 405, Office Block, Hotel Equatorial Shanghai

No.65, Yan An Road (West), Shanghai, 200040, China 中国上海市延安西路65号上海国际贵都大饭店办公楼405单元

Phone: +86-21-62489820

Fax: +86-21-62489821 
www.intechopen.com 
(C) 2008 The Author(s). Licensee IntechOpen. This chapter is distributed under the terms of the Creative Commons Attribution-NonCommercialShareAlike-3.0 License, which permits use, distribution and reproduction for non-commercial purposes, provided the original is properly cited and derivative works building on this content are distributed under the same license. 